\title{
ARAŞTIRMA/RESEARCH \\ Yatarak tedavi gören obsesif kompulsif bozukluk hastalarının klinik özellikleri
}

\author{
Clinical features of psychiatric inpatients with obsessive compulsive disorder
}

Gonca Karakuş ${ }^{1}$, Lut Tamam ${ }^{1}$

${ }^{1}$ Çukurova Üniversitesi Tıp Fakültesi Ruh Sağlığı ve Hastalıkları Anabilim Dalı, Adana, Turkey

\begin{abstract}
Purpose: The aim of this study was to determine the clinical and sociodemographic characteristics of the inpatients admitted in a university psychiatry clinic with a diagnosis of obsessive-compulsive disorder in ten years period.

Material and Methods: Patients who had been diagnosed with obsessive compulsive disorder according to DSM IV TR and hospitalized in Cukurova University Faculty of Medicine Balcalı Hospital Department of Psychiatry between 2006 and 2015 were included. Data were obtained from hospital records of patients. Sociodemographic and clinical data form was completed by scanning previous patient files. Patients were grouped according to the gender, age of onset and the family history of psychiatric disorders and these groups were compared.

Results: Forty one of the patients were female $(57.7 \%)$ and 30 of them were male $(42.3 \%)$. Mean age of patients was $25 \pm 10,04$ years; first treatment age was $27.75 \pm 9.19$ and mean duration of untreated illness was $32.82 \pm 48.06$ months. There was a significant difference in patients, when first treatment age and mean duration of untreated illness were examined by gender. In patients with family history of obsessive-compulsive disorder, the mean duration of untreated illness was higher.

Conclusion: Obsessive compulsive disorder is a chronic disorder with significant risk factors for prognosis.

Key words: Obsession, compulsion, inpatients
\end{abstract}

\section{GİRİŞ}

Obsesif kompulsif bozukluk(OKB), yineleyici obsesyonlar ve/veya kompulsiyonların görüldüğü, genellikle süreğen, kimi zamanda epizodik gidiş gösteren, kişinin günlük işlevlerini belirgin olarak

\section{Öz}

Amaç:. Bu çalşmada, psikiyatri servisinde yatarak tedavi gören obsesif kompulsif bozukluk tanılı hastaların sosyodemografik ve klinik özelliklerinin belirlenmesi; hastalık başlangıç yaşının, tedaviye başvurana kadar geçen sürenin ve özkıyım girişiminin sosyodemografik ve klinik değişkenlerle ilişkisinin değerlendirilmesi amaçlanmıştır.

Gereç ve Yöntem: Çalışmada 2006-2015 yılları arasında yatarak tedavi gören obsesif kompulsif bozukluk hastalarının dosyaları değerlendirilmiş; sosyodemografik ve klinik değişkenler belirlenmiş; cinsiyete, ailede ruhsal hastalık ve obsesif kompulsif bozukluk varlığına göre değişkenler arasındaki farklar araștırılmıștır.

Bulgular: Çalışmaya 41 kadın, 30 erkek 71 hasta dahil

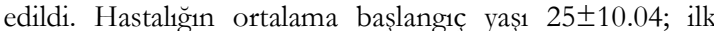
tedavi yaș $27.75 \pm 9.19$; hastalık belirtilerinin bașlamasından ilk tedaviye kadar geçen süre $32.82 \pm 48.06$ ay olarak belirlendi. Kadınlarda ilk tedavi yaşının ve başlangıç ile ilk tedavi arasındaki sürenin fazla; ailede obsesif kompulsif bozukluk öyküsü olan hastalarda tedavisiz geçen sürenin anlamlı olarak yüksek olduğu saptandı.

Sonuç: Obsesif kompulsif bozukluk sonlanım açısından ciddi risk faktörleri olan bir kronik bozukluktur.

Anahtar kelimeler: Obsesyon, kompulsiyon, yatan hasta

etkileyen bir hastalıktır ${ }^{1}$. OKB yaygınlığ1 genel popülasyonda $\% 2-3$ oranında görülen bir hastalıktır ${ }^{2}$. Kadınlarda daha sık ya da kadın erkek eşit oranda görüldüğünü bildiren çalışmalar vardır ${ }^{3}$. Tipik olarak geç ergenlikte ya da erken erişkinlikte başlamaktadır. Başlangıç yaşının 20’li yaşların başları olduğu 
bildirilmiştirr ${ }^{1,4,5}$. Çeşitli yayınlarda hastalığın başlangıcından itibaren bir hekime başvurana kadar geçen sürenin ise 2.3-13.25 yil olduğu bildirilmiştir ${ }^{6,7}$.

OKB'li erişkin hastaların \%30-50'si başlangıcın çocuklukta olduğunu, üçte ikisi ise belirtilerin 15 yaşından önce başladığını bildirmişlerdirr ${ }^{8}$. Birçok çalışmanın ortak bulgusu, erkeklerde hastalığın kadınlara göre daha erken yaşlarda başladığıdır 4,9,10. Erken başlangıcın OKB'de ayırt edici bir özellik olduğu; erken ve geç başlangıçlı erişkin hastalar arasında obsesif-kompulsif belirtilerin sayısı, dağılımı ve şiddeti açısından farklilıkların olduğu bildirilmiştir ${ }^{11}$. OKB hastalarında eşlik eden kişilik özelliklerinin yol açtıkları uyum sorunlarının hastaların evlenmemelerine ya da evli iseler sorun yaşamalarına yol açtığ bildirilmektedir ${ }^{12}$. OKB hastalarında araştırılan bir başka konu ise ailesel geçiş özelliğidir. OKB hastalarında yapılan aile çalışmalarından, OKB hastaları ile OKB'si olan birinci derece akrabalar arasında anlamlı bir ilişki saptanmıştır. Çeşitli araştırmalarda obsesif kompulsif bozukluğu olan hastaların birinci derece akrabalarında \%6-40 oranında psikiyatrik bozukluk olduğu bildirilmiştir ${ }^{1,7,13}$.

OKB kronik seyir, yüksek komorbidite ve tedavi direnci ile karakterize olmasına rağmen; OKB'de özkıyım eğilimine neden olan risk faktörleri diğer anksiyete bozukluklarına göre az çalışılmıştır ve bu konudaki veriler çelişkilidir ${ }^{14}$. $\mathrm{Bu}$ çalışmada, psikiyatri servisinde yatarak tedavi gören obsesif kompulsif bozukluk tanılı hastaların sosyodemografik ve klinik özelliklerinin belirlenmesi; hastalık başlangı̧ yaşının, tedaviye başvurana kadar geçen sürenin ve özkıyım girişiminin sosyodemografik ve klinik değişkenlerle ilişkisinin değerlendirilmesi amaçlanmıştır.

\section{GEREÇ VE YÖNTEM}

Çalıșmamızda Çukurova Üniversitesi Tip Fakültesi Psikiyatri Kliniğinde 2006-2015 y1lları arasında OKB tanisıyla yatırılarak izlenen hastaların dosylarından elde edilen bilgiler değerlendirildi. Çalışma için Çukurova Üniversitesi Tip Fakültesi Girişimsel Olmayan Klinik Araştırmalar etik kurulundan 15 Temmuz 2016 tarih 55/8 karar no ile etik kurul onayı alındi. Psikiyatri kliniğimiz 30 hasta yatağ 1 kapasiteli, ağırlıklı olarak psikotik bozukluklar ve duygudurum bozukluğu hastalarının yatırıldığı, yıllık yatış sayısının 300-350 olduğu, yatan hastalar için giriş çıkışların kontrollü olduğu bir kliniktir. Bu çalışma için öncelikle 10 yıllık sürede yatan hasta dosyaları taranarak obsesif kompulsif bozukluk tanısı olanlar belirlendi. Bu dosyalar içerisinden bu çalışma için hazırladığımız sosyodemografik veri ve klinik özellikler formlarındaki bilgileri elde edebildiğimiz dosyalar seçilerek çalışmaya dahil edildi.

Veri toplama formu: Hastaların yaş, cinsiyet, medeni durum, eğitim, gibi genel sosyodemografik verileri ile hastalık başlangıç yaşı, hastalık süresi, tedaviye başlama yaşı, obsesyon ve kompulsiyonların tipi, ailede hastalık öyküsü, yatış sayısı, yatış süresi, özkıyım girişimi, uygulanan tedavi şekli gibi değişkenlerin yer aldığı bir form hazırlandı. Dosya içerikleri taranarak dolduruldu. Formları dolduracak bilgilerin olmadığı dosyalar çalışma dışı bırakıldı. Çalışmada hastaların genel sosyodemografik özellikleri belirlendi. Cinsiyete, aile öyküsünde ruhsal hastalık ve $\mathrm{OKB}$ varlığına göre sosyodemografik ve klinik özellikler karşılaştırıldı.

\section{İstatistiksel analiz}

Tüm istatistiksel değerlendirmeler SPSS for Windows 15,0 paket programı yardımıla yapıldı. Verilerin değerlendirilmesinde tanımlayıcı istatistiksel yöntemlerin (ortalama, standart sapma) yanı sıra çoklu grupların karşılaştırmasında bağımsız gruplar t-testi, nitel verilerin karşılaştırmalarında kikare testi kullanılmıştır. Sonuçların anlamlılığı $\mathrm{p}<0,05$ olarak kabul edilmiştir.

\section{BULGULAR}

Çalışmaya 2006-2015 yılları arasında yatarak tedavi edilen 41(\%57.7)'i kadın 71 hasta dahil edildi. Çalışmaya dahil edilen tüm hastaların yaş ortalamaları $34.70 \pm 12.36$; kadın hastaların yaş ortalamaları $36.51 \pm 11.38$; erkek hastaların yaş ortalamaları ise $32.23 \pm 13.39$ yildı. Kadın ve erkeklerin yaş ortalamaları arasındaki fark anlamlı değildi $(\mathrm{p}=0.151)$. Hastaların ortalama hastalık süresi $9.85 \pm 8.31$ yıldı. Hastaların genel sosyodemografik ve klinik özellikleri Tablo 1'de gösterilmiştir.

Hastaların genel klinik özellikleri değerlendirildiğinde obsesif kompulsif belirtilerin başlama yaşı 8-49 arasında idi. Ortalama başlangıç

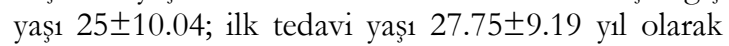
belirlendi. Hastalık belirtilerinin başlamasından ilk tedaviye kadar geçen süre 1-230 ay arasinda, ortalama $32.82 \pm 48.06$ aydı. Hastaların şimdi ve 
geçmişte görülen obsesyon ve kompulsiyon sıklıkları Tablo 2'de verilmiştir. En sık görülen obsesyon tipi kirlenme (\%66.2). kompulsiyon tipi ise temizlik/yıkama idi.

Tablo 1. Yatarak tedavi göre obsesif kompulsif bozukluk hastalarının sosyodemografik ve klinik özellikleri

\begin{tabular}{|c|c|c|}
\hline & $\mathrm{n}(\mathrm{N}=71)$ & $\%$ \\
\hline \multicolumn{3}{|l|}{ Cinsiyet } \\
\hline -Kadın & 41 & 57.7 \\
\hline -Erkek & 30 & 42.3 \\
\hline \multicolumn{3}{|l|}{ Medeni Durumu } \\
\hline -Bekar & 32 & 45.1 \\
\hline -Evli & 39 & 54.9 \\
\hline \multicolumn{3}{|l|}{ Ĕgitim } \\
\hline -Eğitimsiz/okur-yazar değil & 6 & 8.4 \\
\hline -ìlköğretim & 23 & 32.4 \\
\hline -Lise & 23 & 32.4 \\
\hline -Yüksekokul-üniversite & 19 & 26.8 \\
\hline Ailede Ruhsal Bozukluk & 40 & 56.3 \\
\hline Ailede Obsesif Kompulsif Bozukluk & 16 & 22.5 \\
\hline Sigara Kullanımı & 30 & 42.3 \\
\hline Alkol Kullanımı & 4 & 5.6 \\
\hline Madde Kullanımı & 1 & 1.4 \\
\hline Başlangıçta stres etkeni & 25 & 35.2 \\
\hline EKT öyküsü & 20 & 28.2 \\
\hline Özkıyım girişimi & 13 & 18.3 \\
\hline \multicolumn{3}{|l|}{ Özkııım şekli } \\
\hline -İlaç/zehir & 9 & 12.7 \\
\hline -Atlama & 1 & 1.4 \\
\hline -Çoklu & 3 & 4.2 \\
\hline \multicolumn{3}{|l|}{ Yatarken kullanılan ilaç tedavisi } \\
\hline -Antidepresan & 19 & 26.8 \\
\hline -Antidepresan+Antipsikotik & 48 & 67.6 \\
\hline -Diğer & 4 & 5.6 \\
\hline \multicolumn{3}{|l|}{ Yatarken EKT uygulaması } \\
\hline -Var & 10 & 14 \\
\hline -Yok & 61 & 86 \\
\hline
\end{tabular}

Tablo 2. Obsesif kompulsif bozukluk hastalarının obsesyon ve kompulsiyon tiplerinin görülme sıklıkları

\begin{tabular}{|l|c|c|}
\hline & Şimdi & Geçmişte \\
\hline Obsesyon tipi & $16(\% 22.5)$ & $15(\% 21.1)$ \\
\hline -saldırganlı & $47(\% 66.2)$ & $45(\% 63.4)$ \\
\hline -kirlenme & $10(\% 14.1)$ & $10(\% 14.1)$ \\
\hline -cinsel & $7(\% 9.9)$ & $7(\% 9.9)$ \\
\hline -biriktirme/saklama & $18(\% 25.4)$ & $21(\% 29.6)$ \\
\hline -dini & $12(\% 16.9)$ & $14(\% 19.7)$ \\
\hline -simetri/düzen & $13(\% 18.3)$ & $13(\% 18.3)$ \\
\hline -somatik & $29(\% 40.8)$ & $26(\% 36.6)$ \\
\hline -diğer & \multicolumn{2}{|c|}{} \\
\hline Kompulsiyon tipi & $47(\% 66.2)$ & $46(\% 64.8)$ \\
\hline -temizlik/yıkama & $23(\% 32.4)$ & $24(\% 33.8)$ \\
\hline -kontrol etme & $21(\% 29.6)$ & $20(\% 28.2)$ \\
\hline -törensel davranış & $8(\% 11.3)$ & $10(\% 14.1)$ \\
\hline -sayma & $9(12.7)$ & $6(\% 15.5)$ \\
\hline -siralama/düzenleme & $4(\% 5.6)$ & $29(\% 40.8)$ \\
\hline -biriktirme/toplama & $31(\% 43.7)$ & \\
\hline -diğer & \multicolumn{2}{|c|}{} \\
\hline
\end{tabular}


Hastalar cinsiyetlerine göre klinik özelliklerin karșılaștırılması Tablo 3'te verilmiștir. Kadın ve erkeklerde obsesif kompulsif belirti başlama yaşları arasında anlamlı fark yokken; ilk tedavi yaşı kadınlarda anlamlı şekilde yüksek ve başlangıç ile ilk tedavi arasındaki süre fazla idi..

Tablo 3. Cinsiyetlere göre klinik değişkenlerin karşılaştırılması.

\begin{tabular}{|c|c|c|c|}
\hline & $\begin{array}{l}\text { Kadın } \\
(n=41)\end{array}$ & $\begin{array}{l}\text { Erkek } \\
(n=30)\end{array}$ & $\mathbf{P}$ \\
\hline Ortalama yatış sayısı & $2.10 \pm 2.67$ & $2.00 \pm 1.34$ & 0.855 \\
\hline Ortalama yatış süresi(gün) & $28.70 \pm 13.17$ & $33.70 \pm 17.55$ & 0.175 \\
\hline OKB başlangıç yaşı ort & $26.17 \pm 9.41$ & $23.40 \pm 10.82$ & 0.254 \\
\hline OKB ilk tedavi yaşı ort & $29.85 \pm 7.63$ & $24.87 \pm 10.42$ & $0.023^{*}$ \\
\hline Başlangıç-ilk tedavi arası süre(ay) & $44.49 \pm 58.97$ & $16.87 \pm 17.92$ & $0.016^{*}$ \\
\hline Özkıyım girişimi $(\%)$ & $9(\% 22)$ & $4(13.3)$ & 0.354 \\
\hline Şimdiki Obsesyon tipi & $\%$ & $\%$ & \\
\hline -saldirganlik & 8 & 8 & 0.476 \\
\hline -kirlenme & 34 & 13 & $<0.0001^{*}$ \\
\hline -cinsel & 5 & 5 & 0.593 \\
\hline -biriktirme/saklama & 4 & 3 & 0.973 \\
\hline -dini & 5 & 13 & $0.003^{*}$ \\
\hline -simetri/düzen & 7 & 5 & 0.964 \\
\hline -somatik & 4 & 9 & $0.029 *$ \\
\hline -diğer & 15 & 15 & 0.393 \\
\hline \multicolumn{4}{|l|}{ Şimdiki kompulsiyon tipi } \\
\hline -temizlik/y1kama & 34 & 13 & $0.000^{*}$ \\
\hline -kontrol etme & 11 & 12 & 0.241 \\
\hline -törensel davranış & 6 & 15 & $0.001 *$ \\
\hline -sayma & 3 & 5 & 0.218 \\
\hline -sıralama/düzenleme & 5 & 4 & 0.887 \\
\hline -biriktirme/toplama & 0 & 4 & $0.016^{*}$ \\
\hline -diğer & 11 & 20 & $0.001 *$ \\
\hline
\end{tabular}

Hastalar ailede psikiyatrik hastalık ve $\mathrm{OKB}$ varlığına göre birbirleri ile karşılaştırıldığında elde edilen veriler Tablo 4'te verilmiştir. Ailede psikiyatrik hastalık öyküsü olanlarla olmayanlar yatış sayısı, ortalama yatış süresi, obsesif kompulsif belirti başlama yaşı, tedavisiz geçen süre ve ilk tedavi yaşı açısından karşılaştırıldığında anlamalı fark bulunmazken; ailede OKB öyküsü olan hastalar olmayanlarla karşılaştırıldığında tedavisiz geçen süre anlamlı olarak yüksek bulundu $(\mathrm{p}=0.012)$.

\section{TARTIŞMA}

Çalışmamızda üniversite hastanesinde yatarak tedavi gören $71 \mathrm{OKB}$ hastası değerlendirildi. Hastalarda OKB ortalama başlangıç yaşı $25 \pm 10.04$; ilk tedavi yaş1 27.75 \pm 9.19 ; ilk tedaviye kadar geçen tedavisiz hastalık süresi $32.82 \pm 48.06$ aydı. En sık görülen obsesyon tipi kirlenme $(\% 66.2)$. kompulsiyon tipi ise temizlik/yıkama idi. Hastalar cinsiyet açısından değerlendirildiğinde kadınlarda erkeklere göre anlamlı şekilde ilk tedaviye kadar geçen süre uzun ve ilk tedavi yaşı yüksek; kirlenme obsesyonları, temizlik kompulsiyonları s1ktı. Erkeklerde ise dini ve somatik obsesyonlar ile törensel davranış ve biriktirme kompulsiyonları istatistiksel olarak anlamlı şekilde sıktı. Ailede ruhsal hastalık varlı̆̆ına göre klinik değişkenler değerlendirildiğinde anlamlı fark saptanmazken; ailede okb öyküsü varlı̆̆ında ilk tedaviye kadar geçen hastalık süresi anlamlı olarak yüksek bulundu.

OKB'nin cinsiyete göre dağılımını araştırmalarda kadın ve erkek eşit dağılım gösterdiğini ya da kadınlarda daha sık olduğunu gösteren çalıșmalar vardır ${ }^{1,3}$. Ülkemizde son yillarda ayaktan OKB hastalarının değerlendirildiğ çalışmalarda \%57.3$\%$ k1.4 kadın oranları bildirilmiştir ${ }^{7,15,16}$. Bizim 
çalışmamızda da yatan hastalar içerisinde kadınların daha fazla olduğu görülmüştür. OKB tipik olarak geç ergenlikte ya da erken erişkinlikte başlamaktadır. Başlangıç yaşı genellikle 20'li yaşların başı olarak bildirilmiştir ${ }^{1,4,5}$. Poyraz ve ark.nın ülkemizde yaptığ1 çalışmada ortalama hastalık başlangıç yaşı $19.71 \pm 9.15$ ve ilk tedavi başvurusuna kadar geçen

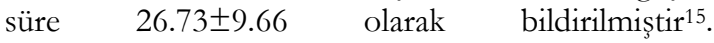
Çalışmamızda ortalama OKB başlangıç yaşı 25 10.04; hastalık başlangıcından etkin tedaviye kadar geçen süre ortalama $32.82 \pm 48.06$ ay olarak belirlenmiştir ve genel literatürle uyumlu olarak bulunmuştur.
Literatürde hastalığın erkeklerde kadınlara göre erken başladığını gösteren çalışmalar bulunmaktadır ${ }^{4,9,10}$.

Çalışmamızda ise hastalık başlangıç yaşı açısından kadın ve erkekler arasında anlamlı fark olmadığı; ancak kadınlarda tedaviye başvurunun daha geç olduğu belirlenmiştir. Ülkemizde yapılan OKB hastalarında tedavisiz hastalık süresinin araştırıldığ1 çalışmada ise erkek hastaların \%46,34'ünün; kadın hastaların \%49,09'unun tedaviye 4 yıldan daha geç dönemde başvurdukları belirlenmiştir ${ }^{15}$.

Tablo 4. Ailede psikiyatrik hastalık ve obsesif kompulsif bozukluk varlığına göre klinik değişkenlerin karşılaştırılması

\begin{tabular}{|c|c|c|c|c|c|c|}
\hline & \multicolumn{2}{|c|}{ Ailede psikiyatrik hastalık } & & \multicolumn{2}{|c|}{ Ailede okb } & \multirow[b]{2}{*}{$\mathbf{P}$} \\
\hline & $\operatorname{Var}(n=40)$ & Yok $(n=31)$ & $\mathrm{p}$ & $\operatorname{Var}(\mathrm{n}=16)$ & Yok $(\mathrm{n}=55)$ & \\
\hline Ortalama yatış sayısı & $1.78 \pm 1.21$ & $2.42 \pm 3.02$ & 0.223 & $1.75 \pm 1.00$ & $2.15 \pm 2.44$ & 0.530 \\
\hline Ortalama yatış süresi(gün) & $31.50 \pm 14.89$ & $29.94 \pm 15.93$ & 0.672 & $30.13 \pm 13.13$ & $31.02 \pm 15.93$ & 0.838 \\
\hline OKB başlangıç yaş1 ort & $24.60 \pm 9.85$ & $25.52 \pm 10.44$ & 0.706 & $26.81 \pm 10.98$ & $24.47 \pm 9.81$ & 0.416 \\
\hline OKB ilk tedavi yaşı ort & $27.23 \pm 8.82$ & $28.42 \pm 9.75$ & 0.591 & $31.69 \pm 6.98$ & $26.60 \pm 9.48$ & 0.051 \\
\hline $\begin{array}{l}\text { Başlangıç-ilk tedavi arası } \\
\text { süre(ay) }\end{array}$ & $30.95 \pm 55.35$ & $35.23 \pm 37.35$ & 0.713 & $59.06 \pm 77.26$ & $25.18 \pm 32.74$ & $0.012 *$ \\
\hline Şimdiki Obsesyon tipi & $\%$ & $\%$ & & $\%$ & $\%$ & \\
\hline -saldırganlık & 7 & 9 & 0.249 & 3 & 13 & 0.681 \\
\hline -kirlenme & 26 & 21 & 0.809 & 12 & 35 & 0.398 \\
\hline -cinsel & 5 & 5 & 0.663 & 1 & 9 & 0.306 \\
\hline -biriktirme/saklama & 4 & 3 & 0.964 & 2 & 5 & 0.687 \\
\hline -dini & 10 & 8 & 0.938 & 2 & 16 & 0.179 \\
\hline -simetri/düzen & 5 & 7 & 0.261 & 2 & 10 & 0.594 \\
\hline -somatik & 8 & 5 & 0.676 & 3 & 10 & 0.959 \\
\hline -diğer & 16 & 13 & 0.869 & 6 & 23 & 0.757 \\
\hline Şimdiki kompulsiyon tipi & & & & & & \\
\hline -temizlik/y1kama & 26 & 21 & 0.809 & 12 & 35 & 0.398 \\
\hline -kontrol etme & 15 & 8 & 0.296 & 7 & 16 & 0.270 \\
\hline -törensel davranış & 13 & 8 & 0.540 & 2 & 19 & 0.089 \\
\hline -sayma & 3 & 5 & 0.254 & 0 & 8 & 0.105 \\
\hline -siralama/düzenleme & 2 & 7 & $0.027 *$ & 0 & 9 & 0.083 \\
\hline -biriktirme/toplama & 2 & 2 & 0.792 & 0 & 4 & 0.267 \\
\hline -diğer & 18 & 13 & 0.796 & 3 & 28 & $0.022 *$ \\
\hline
\end{tabular}

Yatan hastalarda yapılan bu çalışmada saptadığımız ortalama hastalık süresi $9.85 \pm 8.31$ yıldır ve ülkemizde yapilan ve ayaktan hastaların değerlendirildiği bir çalışmada ${ }^{15}$ saptanan ortalama hastalık süresine (12.78 \pm 10.22 yil) göre düşüktür. $\mathrm{OKB}$ hastalar1 ile $\mathrm{OKB}$ 'si olan birinci derece akrabalar arasında anlamlı bir ilişki saptanmış tır. Aile çalışmalarının sonuçları, $\mathrm{OKB}$ hastalarında ailesel kümelenmeyi destekleyici niteliktedir ${ }^{1,7,13}$. Çalışmamızda da hastaların \%22.5'inde birinci derece akrabalarda aile öyküsü olduğu gösterilmiştir. 84 ailesel, 80 sporadik OKB hastasının birbiri ile karşılaştırıldığı bir çalışmada ailede OKB varlığı erken başlangıç yaşı, tedavisiz geçen hastalık süresinin uzunluğu, tedaviye yanıtsılılk oranlarının yüksekliği ve yüksek komorbidite ile 
ilișkilendirilmiștir ${ }^{17}$. 152 ailesel, 650 sporadik OKB hastasının değerlendirildiği bir çalışmada ise ailesel olgularda bulaş, biriktirmeve simetri obsesyonlarının; yıkama, törensel davranıș ve düzenleme kompulsiyonlarının fazla olduğu gösterilmiştir ${ }^{18}$. Çalışmamızda da aile öyküsünde $\mathrm{OKB}$ varlığ1 olan hastalarda ilk tedaviye kadar geçen sürenin daha yüksek olduğu belirlenmiştir. Ancak obsesyon ve kompulsiyonlar açısından ailede OKB öyküsü varlığ1 ile ilişkili bir fark saptanmamıştır.

OKB hastalarında özkıyım sıklığı ile ilgili veriler çelişkilidir. Özkııım girişimi oranları \%10-27 aralığında bildirilmiştir ${ }^{19-21}$. Bizim çalışmamızda da literatürle uyumlu şekilde (\%18.3) özkıyım girişimi oranları saptand1, en sık uygulanan girişim şekli ise ilaç/zehir içerek özkıyım girişimi idi. Kadın ve erkeklerde özkııım girişimi sıklı̆̆ı açısından anlamlı fark saptanmadi.

Çalışmamızın kısıtlılıkları hasta sayısının görece az olduğu geriye dönük bir çalışma olmasıdır. Özellikle aile öyküsünde $\mathrm{OKB}$ olan hastalarda tedaviye başvuru süresinde gecikme olması literatürde az gösterilmiş bir bulgudur ve çalısmamızda bunu desteklemiştir. Organik ve psikiyatrik hastalıklar için bilinçlenmenin erken tanı ve tedaviye başvuru açısından önemli olduğu bilinse de ailede OKB olan hastaların tedaviye daha geç başvurmaları dikkat çekicidir. Ailede $\mathrm{OKB}$ olan hastalarda tedaviye başvuru süresinin ve bunu etkileyen değişkenlerin araştırılacağ1 ileriye dönük ve daha fazla hastanın dahil edileceği çalışmalara ihtiyaç vardır.

\section{KAYNAKLAR}

1. Tükel R. Obsesif kompulsif bozukluk. Turkiye Klinikleri J Psychiatry-Special Topics. 2010;3:70-80.

2. Sadock B, Sadock VA. Comprehensive textbook of psychiatry 8th. Ed. vol:2, Lippincott Williams \& Wilkins New York. 2007;1768-80.

3. Degonda M, Wyss M, Angst J. The Zurich Study XVIII. Obsessive- compulsive disorders and syndromes in the general population. Eur Arch Psychiatry Clin Neurosci. 1993;243:16-22.

4. Lensi P, Cassano GB, Correddu G, Ravagli S, Kunovac JL, Akiskal HS. Obsessive compulsive disorder: familial-developmental history, symptomatology, comorbidity and course with special reference to gender-related differences. $\mathrm{Br} \mathrm{J}$ Psychiatry. 1996;169:101-7.

5. Tükel R, Ertekin E, Batmaz S, Alyanak F, Sözen A, Aslantaş B et al. Influence of age of onset on clinical features in obsessive-compulsive disorder. Depress Anxiety. 2005;21:112-7.
6. Eğrilmez A, Gülseren L, Aydemir Ö, Kültür S. Obsesif kompulsif bozuklukta fenomenolojik özellikler. 3P Dergisi. 1995;3:9-14.

7. Karamustafalığlu O, Ceylan YC, Bakım B, Toker SG, Bozkurt S, Göksan B et al. Obsesif kompulsif bozukluk hastalarında sosyodemografik özellikler ve komorbidite. ŞEEAH Tip Bülteni. 2009;43:112-6.

8. Rapoport JL. The waking nightmare: an overview of obsessive compulsive disorder. J Clin Psychia-try 1990;51:25-8.

9. Rasmussen SA, Eisen JL. The epidemiology and clinical features of obsessive compulsive disorder. Psychiatr Clin North Am. 1992;15:743-58.

10. Tükel R, Polat A, Genç A, Bozkurt O, Atlı H. Gender-related differences among the Turkish patients with obsessive-compulsive disorder. Compr Psychiatry. 2004;45:362-6.

11. Tükel R, Demet MM, Topçuoğlu V. Obsesifkompulsif bozukluğun fenomenolojisi. Anksiyete Bozuklukları, Tükel R, Alkın T(editorler). 1. Baskı. Ankara: Pozitif Matbaacilık. 2006:277-98.

12. Karno M, Golding JM, Sorenson SB, Burnam MA. The epidemiology of obsessive-compulsive disorder in five US communities. Arch Gen Psychiatry. 1988;45:1094-9.

13. Juang YY, Liu CY. Phenomenology of obsessivecompulsive disorder in Taiwan. Psychiatry Clin Neurosci. 2001;55:623-7.

14. Balci V, Sevincok L. Suicidal ideation in patients with obsessive-compulsive disorder. Psychiatry Res. 2010;175:104-8.

15. Poyraz CA, Turan S, Saglam NGU, Batun GC, Yassa A, Duran A. Factors associated with the duration of untreated illness among patients with obsessive compulsive disorder. Compr Psychiatry. 2015;58:8893.

16. Altıntaș E, Özçürümez G. Obsesif kompulsif bozukluk tanılı hastaların cinsiyet farklılığı açısından değerlendirilmesi. Cukurova Medical Journal. 2015;40:409-17.

17. Viswanath B, Narayanaswamy JC, Cherian AV, Reddy YCJ, Math SB. Is familial obsessivecompulsive disorder different from sporadic obsessive compulsive disorder? A comparison of clinical characteristics, comorbidity and treatment response. Psychopathology. 2011;44:83-9.

18. Arumugham SS, Cherian AV, Baruah U, Viswanath B, Narayanaswamy JC, Math SB et al. Comparison of clinical characteristics of familial and sporadic obsessive compulsive disorder. Compr Psychiatry. 2014;55:1520-5.

19. Torres AR, Prince MJ, Bebbington PE, Bhugra D, Bhugra TS, Farrell M, et al. Obsessive-compulsive disorder: prevalence, comorbidity, impact, and helpseeking in the British National Psychiatric Morbidity Survey of 2000. Am J Psychiatry. 2006;163:1978-85. 
20. Kamath P, Reddy YCJ, Kandavel T. Suicidal behavior in obsessive-compulsive disorder. J Clin Psychiatry. 2007;68:1741-50.

21. Torres AR, de Abreu Ramos-Cerqueira AT, Torresan
RC, de Souza Dominques M, Hercos AC, Guimaraes $\mathrm{AB}$. Prevalence and associated factors for suicidal ideation and behaviors in obsessive- compulsive disorder. CNS Spectr. 2007;12:771-8. 